\title{
English oral presentation for Bachelor of Arts of the four year international student at MCU Chiang Mai campus Thailand
}

\author{
Phra Natthakit Kittiyano (Thaipattana), Winai Siabthaisong \\ Graduate School Mahachulalongkornrajavidyalaya University, 79 M.1, Phahon Yothin Road, Kilometer 55 Lam Sai, Wang Noi, \\ Phra Nakhon Si Ayutthaya, 13170, Thailand \\ Corresponding author: sktsangha@gmail.com
}

\section{ARTICLE INFO}

\section{Article history:}

Received 11 December 2020

Revised 24 February 2021

Accepted 17 March 2021

Available online 15 July 2021

\section{Keywords:}

english, oral presentation, speaking

DOI: 10.26905/enjourme.v6i1.5150

\section{How to cite the article:}

Kittiyano (Thaipattana), P., \& Siabthaisong, W. (2021). English oral presentation for Bachelor of Arts of the four year international student at MCU Chiang Mai campus Thailand. EnJourMe (English Journal of Merdeka) : Culture, Language, and Teaching of English, 6(1) 18-35. doi:h t tps: / /doi. org/10. 26905 /enjourme.v6i1.5150

\begin{abstract}
The paper aimed to uncover the problems underneath English oral presentation of the fourth year students majoring in English at Mahachulalongkornrajavidyalaya University, Chiang Mai Campus, Thailand in order to come up with the solution to improve it. The issue is the students find difficulty when it comes to deliver oral presentation in English despite the fact that they have learned English for many years and gained many vocabularies. The methods used are mixed quantitative (questionnaires for students) and qualitative (In-depth Interview with Five Lecturers) approach. It is found that anxiety and shyness play the key setback be hide the scene.
\end{abstract}

(C) 2021 EnJourMe. All rights reserved.

\section{Introduction}

Oral presentations are one of the most common assignments in college courses, and students in all fields desire to disseminate the new knowledge they produce, and this is often accomplished by delivering oral presentations in class. An effective presentation is more than just standing up and giving information. A presenter must consider the best way to communicate the information to the audience by using techniques to create a presentation that is both informative and interesting. There are three main factors that I am going to show, they are problems, solutions and communication of oral presentation. 
This study focused on the use of student's oral presentation in English language classrooms and its impact in speaking skill. The use of oral presentations in MCU classroom is important because of its positive impact on students' proficiency level. Some students who do not like to speak in the classroom; do not have the opportunity to speak English outside, too. Thus, if the students do not often practice English in the classroom, they may never speak English at all. The students cannot learn to speak any language by observation. Therefore, giving an oral presentation improves the students' oral proficiency. Teachers can use oral presentation as many ways to deal, encourage and motivate the students' speaking problems. Oral presentation activities provide an excellent opportunity for the learners to develop their skill. Several minutes of speaking, is a structured way to deal, encourage and motivate all skills of giving audiences' information clearly and understandably.

English oral presentation in classroom is beneficial for both side speaker and listener. The speaker has an opportunity to practice to present information by using some techniques. The listener has a chance to learn new knowledge from the speaker. Moreover, they can do more studying English at the same time. In addition, among the presentation, they can learn by asking questions and showing ideas. Thus, it is a great way of learning in a group.

\section{Oral Presentation Skills}

The ability to give an oral presentation is an important skill in a varied range of careers, and training in public speaking can help develop important linguistic and personal qualities in students. Consequently, this activity is a major component of many EST and Communication Studies courses in tertiary institutions. I believe there is also an important place for it in other areas where second language learning takes place. Some teachers already include formal presentations in their courses, realizing that students benefit from the attributes that are demanded. Training in public speaking not only cultivates confidence and clear articulation, but also develops useful research skills and encourages careful planning and preparation in the use of language.

However, many teachers feel they can do little to help students beyond setting a topic, providing class time and offering post-presentation advice. But while this view is understandable, it is also misleading. It is true that the teaching literature offers little assistance on how teachers should either prepare students for public speaking or provide them with worthwhile feedback on their performances. However, detailed help can be offered in the planning and delivery of oral presentations. This skill area can be taught just as systematically as any other in the syllabus if it is treated as a practical step by step process leading to the final presentation.

This short article will briefly outline the sequence of stages in developing oral presentations used at the University of Technology in Papua New Guinea. The approach it offers may be of use to other teachers contemplating this area.

\section{The Oral Presentation Process}

The oral presentation is typically a partly spoken, partly visual form of communication which is designed to inform or persuade and occurs in organizational settings. Time is normally limited and so the successful presentation must be carefully prepared. The speaker must be sure of her facts and 
EnJourMe (English Journal of Merdeka): Culture, Language, and Teaching of English

Vol. 6, No. 1, Juli 2021, pp. 18-35

objectives, have a carefully structured outline, support her talk with visual aids, deliver the presentation clearly and confidently and then handle questions from the floor. Obviously, this is a fairly demanding exercise but it is achievable with an awareness of oral communication skills and the practical experience of how they might be applied. There are seven general stages in the process of developing oral presentation skills: 1) short talks and awareness of oral communication strategies; 2) deciding objectives and gathering facts; 3 ) organizing discourse structure $\&$ developing an outline; 4) preparing supporting visual material; 5) rehearsals \& feedback; 6) delivery of presentation \& handling questions; 7) evaluation (Hyland, 1991).

\section{The Problems of Oral Presentation Skills}

Liow (2008), Wolfe (2008), and Munby (2011) explain that "Researchers and educationalists have been preoccupied lately trying to emphasize the role of oral presentation in students' academic careers, especially at undergraduate and postgraduate levels." El Enein (2011) states that "The majority of those studies were devoted to ways of conducting proper oral presentations. Munby (2011) pointed out that "Some studies, on the other hand, listed the benefits of oral presentation, such as helping the instructors cater to students' learning styles, practicing speaking, providing students with a deep understanding of the presentation topic and providing independent, critical learning to facilitate cooperative learning and to introduce students to technology."

Chuang (2009), El Enein (2011), and Alwi and Sidhu (2013) explain that yet, other studies were concerned with listing the difficulties that students usually face in oral presentation, such as feeling nervous, one of the main difficulties reported facing students in oral presentation was anxiety or fear of speaking. Research has consistently revealed that anxiety can impede the EFL students' production and achievement. Al-Nouh et al. (2014) in addition, some studies investigated the reasons behind students' anxiety, such as lack of vocabulary (Mazdayasna, 2012; Subabý, 2010) while others proposed ways to overcome these difficulties, such as choosing a familiar topic and practicing a lot e.g. Zappa-Hollman (2007).

Turner et al. (2013) in addition, a growing number of studies aimed to investigate the reasons behind students' low performance in oral presentations. Akindele \& Trennepohl (2008), these studies can be grouped under three categories: The first is the personal traits such as shyness or fear of facing audiences, the second is self-confidence and the third is physical appearance. One study found that students' personal traits were the reason behind their feelings of anxiety during oral presentation. Second, the audiences and the instructors were believed to be main reasons for students' unwillingness to present, such as negative evaluations, hard questions, humiliating feedback (Elliot \& Chong, 2005). Wolfe (2008) finally said that the lack of presentation skills was seen to play a crucial role in students' feelings of anxiety (e.g., researching, planning, organizing, practicing, and presenting.

\section{Method}

The present study is a quantitative and survey research. They are categorized in two parts in this study: 1) Finding from the questionnaires research; 2) in-depth interview with five lecturers. Method of questionnaires and analyzing its results gathered from the fourth-year students of Bachelor's 
degree of Mahachulalongkornrajavidyalaya University. The purpose of this study is to explore the problems of English speaking skills for oral presentation and categorize from informants, general academic textbooks, thesis and academic journal along with solving the problems. A group of the 45 fourth year students of English program of Mahachulalongkornrajavidyalaya University, Chiang Mai Campus, Thailand, the second semester of 2019-2020 is purposively selected as the respondents in this study. The reason that the researcher has chosen the fourth-year students, who study in English program as the respondents in this study because they are trained to acquire certain English speaking skills.

The questionnaires consist with general background, opinions and research suggestions. Moreover, the problems of English pronunciation, English vocabulary, English grammar, Confidence of presenter and strategy use of oral presentation to improve oral presentation of Bachelor's degree fourth year students of Mahachulalongkornrajavidyalaya University Chiang Mai Campus. The data obtained from the questionnaires will be analyzed by using statistics including Percentage, Frequency, Means and Standard Deviation (SD.) was used via the Statistical Package for the Social Science.

The nature of the questionnaires in the rating scale used in this study is divided into five levels of Orthopaedics scale with the results as presented in Table 1.

Table 1. The rating scale

\begin{tabular}{lc}
\hline \multicolumn{1}{c}{ Degree of Opinion } & Scores \\
\hline Excellent & 5 \\
Very good & 4 \\
Good & 3 \\
Fair & 2 \\
Poor & 1 \\
\hline
\end{tabular}

According to the Main Value of data derived from each statement was interpreted as the level of the problem of public speaking in English as they are mentioned below:

$\begin{array}{ll}\text { Very high } & 4.50-5.00 \\ \text { High } & 3.50-4.49 \\ \text { Moderately high } & 2.50-3.49 \\ \text { Low } & 1.50-2.49 \\ \text { Very low } & 1.00-1.49\end{array}$

Semi-structured interviews were conducted with the five lecturers; each interview conducted in English and Thai depending on the interviewee's preference, with range in length from approximately 20 minutes. Each interviewee was asked to describe their English speaking skills, what is the problem of learners toward oral presentation, what are the factors contributing to problem of oral presentation and what is the effective way of solving the problem of oral presentation. The Questions for in-depth interview to five lecturers who teach the international program students at MCU, Department of Foreign Languages, Faculty of Humanities, Muang, Chiang Mai Province, Thailand: 
1. How is oral presentation important for your students?

2. Do you assign your students to present? Why?

3. What are your techniques to improve your students for English oral presentation?

4. Do you give some comments after your students have presented? Why?

5. Do you have any suggestions for oral presentation course?

\section{Results and discussion}

\subsection{Result}

\section{Personal information of the participants}

The data analysis results of the respondents are the basic of the students in Academic Year 2017 who are Bachelor of Arts fourth year students in English of Mahachulalongkornrajavidyalaya University Chiang Mai Campus, and the questionnaires are distributed to 45 persons. Thereafter, the researcher uses frequency and percentage to analyze the data as shown in the following table.

Table 2. Status of Participants

\begin{tabular}{lcc}
\hline Status of participants & Frequency & Valid Percent \\
\hline Monk & 44 & 97.8 \\
Laity & 1 & 2.2 \\
Total & 45 & 100.0 \\
\hline
\end{tabular}

After the distribution of the questionnaires to the participants, there were 45 participants who returned the questionnaires. Table 2 shows that the majority of the participants were Bachelor of Arts fourth year monk students in English, consisting of 44 participants or $97.8 \%$, while the minority was Bachelor of Arts, the fourth year laity student in English, consisting of 1 participant or 2.2\%.

Table 3. Participants' nationality

\begin{tabular}{lcc}
\hline Nationality & Frequency & Valid Percent \\
\hline Thai & 5 & 11.1 \\
Myanmar & 38 & 84.4 \\
Lao & 1 & 2.2 \\
India & 1 & 2.2 \\
Total & 45 & 100.0 \\
\hline
\end{tabular}

Table 3 shows that most of participants were Bachelor of Arts fourth year Myanmar students, consisting of 38 participants or $84.4 \%$, while 5 participants or $11.1 \%$ were Bachelor of Arts fourth year Thai students, there is only 1 participant or $2.2 \%$ of Lao student and there is only 1 participant or $2.2 \%$ of Indian student. 
English oral presentation for Bachelor of Arts of the four year international student at MCU Chiang Mai campus Thailand

Table 4. Participants' age

\begin{tabular}{lcc}
\hline Age of participants & Frequency & Valid Percent \\
\hline Between 20-30 years & 32 & 71.1 \\
Between 31-40 years & 10 & 22.2 \\
40 years up & 3 & 5.7 \\
Total & 45 & 100.0 \\
\hline
\end{tabular}

Table 4 shows that average age of participants between 20-30 years, consisting of 32 participants or $71.1 \%$, while 10 participants or $22.2 \%$ had the age between $31-40$ years, and 3 participants or $6.7 \%$ had the age of 40 years up.

\section{The Problems of English Speaking for Oral Presentation}

Table 5. The analysis of English pronunciation

\begin{tabular}{clccc}
\hline No & \multicolumn{1}{c}{ Questions } & $\bar{x}$ & SD & Interpretation \\
\hline 1 & $\begin{array}{l}\text { You have troubles in pronunciation while speaking } \\
\text { English. }\end{array}$ & 3.33 & 1.22 & Medium \\
2 & $\begin{array}{l}\text { You have never had a pronunciation problem. } \\
\text { A native speaker of English understands your }\end{array}$ & 2.80 & 1.14 & Medium \\
$\quad \begin{array}{l}\text { English pronunciation. } \\
\text { When you communicate with an English native }\end{array}$ & 3.24 & 1.44 & Medium \\
speaker, you have never felt shy about your & 3.20 & 1.25 & Medium \\
& $\begin{array}{l}\text { pronunciation. } \\
\text { You can understand the pronunciation spoken by } \\
\text { native English speakers. }\end{array}$ & 3.27 & 1.35 & Medium \\
$\quad$ Total & 3.16 & 1.28 & \\
\hline
\end{tabular}

Table 5 presents the analysis the problems of English oral presentation in the level of English pronunciation. The findings revealed that all of students agreed that they have troubles in pronunciation while speaking English $(\bar{x}=3.33)$ with a standard deviation of 1.22 ; they can understand the pronunciation spoken by native English speakers $(\bar{x}=3.27)$ with a standard deviation of 1.35 ; A native speaker of English understands student's English pronunciation $(\bar{x}=3.24)$ with a standard deviation of 1.44; when students communicate with an English native speaker, they have never felt shy about their pronunciation $(\bar{x}=3.20)$ with a standard deviation of 1.25 ; students have never had a pronunciation problems $(\bar{x}=2.80)$ with a standard deviation of 1.14 .

As a result, the overall means score and standard deviation of pronunciation level of English speaking for oral presentation is $(\bar{x}=3.16)$ and a standard deviation of 1.28: So, it can be interpreted that the participants had a moderately high level. 
EnJourMe (English Journal of Merdeka): Culture, Language, and Teaching of English

Vol. 6, No. 1, Juli 2021, pp. 18-35

Table 6. The analysis of English vocabulary

\begin{tabular}{clccc}
\hline No & \multicolumn{1}{c}{ Questions } & $\bar{x}$ & SD & Interpretation \\
\hline 1 & You have an adequate English vocabulary for & 3.98 & 0.94 & High \\
2 & effective speaking. & 3.58 & 1.05 & High \\
3 & $\begin{array}{l}\text { You have never had any vocabulary problems. } \\
\text { You guess the meaning of new vocabularies. }\end{array}$ & 3.67 & 0.87 & High \\
& $\begin{array}{l}\text { When you do oral presentation, you confidently use } \\
\text { vocabularies. }\end{array}$ & 3.58 & 1.05 & High \\
& $\begin{array}{l}\text { When you preparing a speech, you feel anxious about } \\
\text { your ability to use English vocabularies. }\end{array}$ & 3.87 & 1.10 & High \\
$\quad$ Total & 3.73 & 1.00 & \\
\hline
\end{tabular}

Table 6 illustrates the vocabulary level of English oral presentation. The study results revealed that all of the participants are good at it. They have an adequate English vocabularies for effective speaking $(\bar{x}=3.98)$ with a standard deviation of 0.94 , they feel anxious about their ability to use English vocabularies when they preparing a speech $(\bar{x}=3.87)$ with a standard deviation of 1.10 , they can guess the meaning of new vocabularies $(\bar{x}=3.67)$ with a standard deviation of 0.87 , they confidently use vocabularies, when they do oral presentation $(\bar{x}=3.58)$ with a standard deviation of 1.05 and they have never had a vocabulary problems $(\bar{x}=3.58)$ with a standard deviation of 1.05 as well.

As a result, the overall means score and standard deviation of vocabulary level of English oral presentation. The participants in this study is $(\bar{x}=3.73)$ and a standard deviation of 1.00 which is interpreted as being at a high level.

Table 7. The analysis of English grammar

\begin{tabular}{clccc}
\hline No & \multicolumn{1}{c}{ Questions } & $\bar{x}$ & SD & Interpretation \\
\hline 1 & $\begin{array}{l}\text { You speak English according to English grammar } \\
\text { correctly. }\end{array}$ & 3.98 & 0.94 & High \\
2 & $\begin{array}{l}\text { You confused when you are thinking of grammar while } \\
\text { speaking. }\end{array}$ & 3.58 & 1.05 & High \\
3 & $\begin{array}{l}\text { Does English grammar affects your English-speaking } \\
\text { skills? }\end{array}$ & 3.67 & 0.87 & High \\
4 & $\begin{array}{l}\text { English grammar is not important, you need to } \\
\text { understand and communicate well. }\end{array}$ & 3.58 & 1.05 & High \\
5 & $\begin{array}{l}\text { You're not too serious with English grammar, when } \\
\text { you are speaking. } \quad \text { Total }\end{array}$ & 3.87 & 1.10 & High \\
\hline
\end{tabular}

As indicated in Table 7 which shows that grammar level of English speaking for oral presentation. They speak English according to English grammar correctly $(\bar{x}=3.98)$ with a standard deviation of 0.94 , they are not too serious with English grammar, when they speaking $(\bar{x}=3.87)$ with a standard deviation of 1.10, English grammar effect their English speaking skill $(\bar{x}=3.67)$ with a standard deviation of 0.87 , they confused when they thinking of grammar while they speaking 
English oral presentation for Bachelor of Arts of the four year international student at MCU Chiang Mai campus Thailand

Phra Natthakit Kittiyano (Thaipattana), Winai Siabthaisong

$(\bar{x}=3.58)$ with a standard deviation of 1.05 , a and they need to understand and communicate well, English grammar is not important $(\bar{x}=3.58)$ with a standard deviation of 1.05 .

As a result, the overall means score and standard deviation of grammar level of English speaking for oral presentation. The participants in this study is $(\bar{x}=3.73)$ and a standard deviation of 1.00 which is interpreted as being at a high level.

Table 8. The analysis of lacking of confidence

\begin{tabular}{clccc}
\hline No & \multicolumn{1}{c}{ Questions } & $\bar{x}$ & SD & Interpretation \\
\hline 1 & You feel shy when you are standing in the front of & 3.76 & 0.93 & High \\
2 & many audience. & 3.31 & 1.06 & Medium \\
3 & You fear to make some speaking mistake. & 3.67 & 0.87 & High \\
4 & You don't know how to get audience's attention. & 3.38 & 1.02 & Medium \\
5 & You feel shaky when you presenting your topic. & 3.27 & 1.26 & Medium \\
& Total & 3.47 & 1.02 & \\
\hline
\end{tabular}

Table 8 shows that lacking of confidence of English speaking for oral presentation. They feel shy when they are standing in the front of many audience $(\bar{x}=3.76)$ with a standard deviation of 0.93, they feel nervous when audience looking at them $(\bar{x}=3.67)$ with a standard deviation of 1.36 , they don't know how to get audience's attention $(\bar{x}=3.38)$ with a standard deviation of 1.02 , they fear to make some speaking mistake $(\bar{x}=3.31)$ with a standard deviation of 1.06 and they feel shaky when they present their topic $(\bar{x}=3.27)$ with a standard deviation of 1.26 .

As a result, the overall means score and standard deviation of character of speaker level of English speaking for oral presentation. The participants in this study is $(\bar{x}=3.47)$ and a standard deviation of 1.02 , which is interpreted as being at a moderately high level.

Table 9. The analysis of strategy used in solving the problems

\begin{tabular}{clccc}
\hline No & \multicolumn{1}{c}{ Questions } & $\bar{x}$ & SD & Interpretation \\
\hline 1 & $\begin{array}{l}\text { How much do you have confidence when you do } \\
\text { oral presentation? }\end{array}$ & 3.22 & 1.25 & Medium \\
2 & $\begin{array}{l}\text { How much are you yourself when you do oral } \\
\text { presentation? }\end{array}$ & 3.47 & 1.27 & Medium \\
3 & $\begin{array}{l}\text { Do you smile to your audience in order to gain good } \\
\text { relationship with them? }\end{array}$ & 3.49 & 1.18 & Medium \\
4 & $\begin{array}{l}\text { Do you present according to the structure: } \\
\text { Introduction, Body and Conclusion? }\end{array}$ & 3.78 & 0.95 & High \\
5 & $\begin{array}{l}\text { Do you use body language when you do oral } \\
\text { presentation? }\end{array}$ & 3.69 & 1.14 & High \\
6 & $\begin{array}{l}\text { Do you use visual aids when you do oral } \\
\text { presentation? }\end{array}$ & 2.98 & 1.28 & Medium \\
7 & $\begin{array}{l}\text { Do you play with voices when you do oral } \\
\text { presentation? }\end{array}$ & 3.33 & 1.39 & Medium \\
8 & $\begin{array}{l}\text { Do you have eyes contact with your audience? } \\
\text { Do your present your topic as you are story teller? }\end{array}$ & 3.22 & 1.12 & Medium \\
& $\quad$ Total & 0.96 & Medium \\
\hline
\end{tabular}


EnJourMe (English Journal of Merdeka): Culture, Language, and Teaching of English

Vol. 6, No. 1, Juli 2021, pp. 18-35

Table 9 explains the strategy use of speaking skill for oral presentation. They present according to the structure: Introduction, Body and Conclusion $(\bar{x}=3.78)$ with a standard deviation of 0.95 , they use body language when they do oral presentation $(\bar{x}=3.69)$ with a standard deviation of 1.14 , they smile to their audience in order to gain good relationship $(\bar{x}=3.49)$ with a standard deviation of 1.18 , they are themselves when they do oral presentation $(\bar{x}=3.47)$ with a standard deviation of 1.27 , they play with voices when they do oral presentation $(\bar{x}=3.33)$ with a standard deviation of 1.39 , they have confidence when they do oral presentation $(\bar{x}=3.22)$ with a standard deviation of 1.25 , they have eyes contact with their audience $(\bar{x}=3.22)$ with a standard deviation of 1.12 , they use visual aids when they do oral presentation $(\bar{x}=2.98)$ with a standard deviation of 1.28 and they present their topic as a story teller $(\bar{x}=2.51)$ with a standard deviation of 0.96 .

Total: the overall mean score and standard deviation of the strategy use of speaking skill for oral presentation is $(\bar{x}=3.29)$ with a standard deviation of 1.17 , which is interpreted as being at a moderately high level.

\section{In-depth Interview with Five Lecturers}

Ass.Prof.Dr.Wisuttichai Chaiyasit, instructor of English linguistic subject and English language, Department of Foreign Languages, Faculty of Humanities, MCU.

In conclusion, the performance of sharing information, ideas, thoughts and feeling is called oral presentation. oral presentations are one of the most common assignments in college courses. It is a good opportunity for students to train the communication skills. The more students practice oral presentation, the more confidence they gain. Moreover, students will have creative ideas because they have learned by thinking. Students need to be organized before they give some speeches. They must know how to plan the presentation. For example, focusing presentation on the audience. how much audience can understand, all the details must be informative delivering to the audiences and so on.

Assoc. Prof. Dr. Preecha Kanetnok, Instructor of English Linguistic subject and English Language, Department of Foreign Languages, Faculty of Humanities, MCU.

To summarize, presentation is a great way to create group study, because, the speaker has the role to share the knowledges and ideas, this is called collaborative learning. speaking skills are very essential for oral presentation. Stage is a great place for students to improve presentation skills. Pronunciation is communication system that students need to be skillful, because presenter need to have clear pronunciation so that the audiences can understand correctly. Finally, students need to be themselves when they are giving some speeches, because, being oneself can make the students show full abilities.

Dr. Sasinun Sappakitjamnong, instructor of English linguistic subject and English language, Department of Foreign Languages, Faculty of Humanities, MCU.

In sum up, learning often takes place best when students have opportunities to express ideas and get feedback from their peers. But for feedback to be most helpful to learners, it must consist of more than the provision of correct answers. Feedback ought to be analytical, to be suggestive, and to come at a time when students are interested in it. And then there must be time for students to reflect 
English oral presentation for Bachelor of Arts of the four year international student at MCU Chiang Mai campus Thailand

Phra Natthakit Kittiyano (Thaipattana), Winai Siabthaisong

on the feedback they receive, to make adjustments and to try again a requirement that is neglected, it is worth noting, by most examinations especially final. Presentation is not only standing and giving some speeches, students must know the technique how to use the multimedia and technology such as power point program, video and so on, these tools are going to make the presentation look more colorful

Dr. William Yaryan, Instructor of English Linguistic Subject and English Language, Department of Foreign Languages, Faculty of Humanities, MCU.

In conclusion, confidence is very essential for presenter. Students need to practice more, because practice will make shyness go away. Students should have no fear for making some mistakes, because learning from mistakes they can do it better next time. Students should prepare the information first before they give the speeches, Moreover, student must know the details of topic that they are going to talk very well in order to make the presentation go smoothly.

Asst. Prof. Dr. Samran Khansamrong, he is an Instructor of English Linguistic Subject and English Language, Department of Foreign Languages, Faculty of Humanities, MCU.

To summarize, English speaking skill for oral presentation is very essential nowadays, communication is sending and receiving information between two or more people. The information conveyed can include facts, ideas, concepts, opinions, beliefs, attitudes, instructions and even emotions. It makes people understand more about each other. Of course, it takes time and effort to develop these skills and become an effective communicator. The more effort and practice you put it, the more instinctive and spontaneous your communication skills will become. English as an international language, you will have more opportunities than those who can't speak so that you can develop the qualities of life, institute, society, and even country, for example, I am a monk who can speak English. I can talk to western people about the Buddhism and Thai's culture. I do my duty as a monk by preaching Dhamma, I have the role in society teaching foreigner, I am the representative of Thailand to show how Thai's culture is.

\subsection{Discussions}

In terms of international students (Buddhist monks and a laity), they are Laos, Burmese, Indian, and Thais whose English is a foreign/second language (EFL/ ESL). The majority is 20-30 years old (few are above 40 yrs old). 38 Burmese are majority.

The result in terms of the mean scores interpreted is divided into two main groups; "a high level" and "a moderately high level". Only that of the analysis of Vocabulary and Grammar is in "a high level" group. The rest are in "a moderately high level” group.

In regards with the Table 6 and 7 Analysis of English vocabulary and grammar respectively, the average score interpreted is High for both of them. Since they are the students majoring in English, it is quite general that they tend to pay very much attention to their grammar which highly likely happens to EFL learners. It is reflected that many EFL learners know a lot of vocabularies and grammars, but they cannot speak English well (Chamnan, 2017). Pronunciation is one of the language elements that should be noticed in learning English. Sometimes, learners who are good at grammar 
EnJourMe (English Journal of Merdeka): Culture, Language, and Teaching of English

Vol. 6, No. 1, Juli 2021, pp. 18-35

and vocabulary have a problem with pronunciation because they do not learn it from the beginning as they start learning grammar and vocabulary (Wulandari, 2019). In other words, Sometimes ESL and EFL learners who are good at vocabulary and grammar have some difficulties in pronunciation because they do not learn pronunciation from the early time as they start learning English (Kholisoh \& Farida, 2018). The second language acquirers are often good at vocabulary and grammar. However, they are short of pronunciation (Gao, 2013).

Grammar particularly, many ESL students firmly believe that knowledge of grammar is essential to their ability to acquire a new language (Savage et al., 2010). It is mentioned that many of us, having learned foreign languages via grammar-based methodologies or as a consequence of our teacher training and education, are more comfortable teaching grammar than other language skills (Savage et al., 2010). Another example of SouthEast Asian EFL learners, Vietnamese learners of English are generally passive and dependent and that they are good at grammar, reading and writing, but cannot utter a proper sentence (Tran, 2011). Thai students, since Thais learn English from reading and writing, not listening and speaking, they do not employ natural language learning. They are good at grammar, but they cannot use English for communication (Likitrattanaporn, 2014).

In addition, predominantly when students develop greater fluency and expression in English, it is necessary for them to gain more helpful vocabulary knowledge and expand their own personal vocabulary learning strategies. It is due to the intrinsic nature of language learning that students often recognize the importance of vocabulary (Akkakoson, 2016). Moreover, older learners are particularly good at vocabulary learning, and they can make use of different cognitive and learning skills from children, since they make use of more abstract reasoning and thinking and can often learn more analytically and reflectively (Richards, 2015).

Undoubtedly, the target students are highly likely to be good at vocabulary and grammar. However, the outcome of the analysis of lacking confidence; its mean score interpreted is a moderately high level which is lower than that of vocabulary and grammar analysis. Interestingly, while vocabulary \& grammar analysis are in "high level", that of confidence \& strategy are lower. This is the point. Despite the fact that vocabulary and grammar abilities are good, the oral presentation still needs to be improved because the students tend to be facing issues of shyness, anxiety, and lack of confidence.

In terms of confidence particularly, there are two main factors namely anxiety and shyness. Dr. William Yaryan has shared that his students have difficulty speaking because they are shy and because they are afraid of making mistakes. Then, they think they have nothing to say. A number of Western professors believed ESL students need to overcome cultural inhibition or shyness about speaking up in class, to learn to ask and answer questions effectively, and to communicate more with native speakers of English or less with speakers of their own language. Cheng has shared that twelve professors specifically mentioned Asian students as having cultural differences which inhibited their oral participation in class and their willingness and ability to ask questions (Cheng, 2000).

What is going on in the English presentation among those students, they have fear of making mistakes, shyness, nothing to say, lack of confidence, less practicing, no idea, English language level related and so on. To clarify, among those target students, they have different ability levels in terms of 
English oral presentation for Bachelor of Arts of the four year international student at MCU Chiang Mai campus Thailand

Phra Natthakit Kittiyano (Thaipattana), Winai Siabthaisong

pronunciation, vocabulary, grammar, and strategy used; which are associated with fear, shyness, confidence, and anxiety. For example, on one hand, some students who are good at English tend to have less fear, anxiety, and shyness with more confidence; and are highly likely active students. They like to speak, they enjoy preparing for the presentation, they are active listeners when they are the audience. On the other hand, some students who are not that good English tend to have more fear, anxiety, and shyness with less confidence, and tend to struggle with oral presentation and encounter issues in pronunciation, vocabulary, grammar, and strategy.

Strategy used for solving the problems, an average score interpreted is a moderately high level, shows that the students understand and are aware of what should be done during the presentation as well as realize what strategy can be used and turned out an effective presentation i.e. body language, eyes contact, storytelling, using visual aids, organize the idea and convey the message structurally.

Storytelling is created by a shared human experience based on words and imagination which develops communication skills (Yazdanpanah, 2012). Thus, it is powerful to make use of storytelling to convey the message to hit the attention of the audience and avoid getting them bored.

It is significant to deal with anxiety in order to trigger English oral presentation of the target students. In addition, feedback given by teachers is powerful. Dr.Sasinun mentioned that feedback ought to be analytical, to be suggestive, and to come at a time when students are interested in it. However, it is also undeniable to take time management into consideration.

\section{The problems factors}

In terms of the problems of English speaking in relation to the factors contributing to problems of oral presentation among students in English speaking classes of the target students; it is unquestionable that pronunciation, vocabulary, grammar, confidence, and strategy used are related to English oral presentation of the target students. Interestingly, while vocabulary \& grammar analysis are in "high level", that of confidence \& strategy are lower. This is the key point.

In terms of confidence particularly, there are two main factors namely anxiety and shyness. Dr. William Yaryan mentioned that his students have difficulty speaking because they are shy and afraid of making mistakes. And finally, they think they have nothing to say. It is shown that students' anxiety level had a negative relationship to their oral performance (Leong \& Ahmadi, 2017).

When anxiety is related to learners' second or foreign language learning process, it is known as second/foreign language anxiety. The language anxiety involves a complex, multifaceted reality which may affect the learners in terms of their culture, previous language learning process, learners' characters, and classroom environment. The Language anxiety refers to 'a distinct complex of self-perceptions, beliefs, feelings, and behaviors' which are connected to learners' language learning system. A psychological dimension to language anxiety saying that it is a factor that creates a negative effect on learners' psychology. The anxiety is 'the feeling of tension and apprehension' that appear when learners use a language. So, it can be said that language anxiety is a complicated psychological negative feeling, attitude, and belief of human beings that may be aroused in learners based on different issues when they learn or use a language (Kalra \& Siribud, 2020). 
EnJourMe (English Journal of Merdeka): Culture, Language, and Teaching of English

Vol. 6, No. 1, Juli 2021, pp. 18-35

A number of Western professors believed ESL students need to overcome cultural inhibition or shyness about speaking up in class, to learn to ask and answer questions effectively, and to communicate more with native speakers of English or less with speakers of their own language. Twelve professors specifically mentioned Asian students as having cultural differences which inhibited their oral participation in class and their willingness and ability to ask questions (Cheng, 2000).

However, pronunciation is undeniable to be taken into account of oral presentation ability. As per Lintunen and Skaffari (2014) giving a presentation in L2 (second language) both presented a challenge and provided a way of alleviating the pressure of the situation. The most typical level of L2 identified as a cause of concern by the students was pronunciation.

Dr. Preechar reflects that even if their vocabulary and English grammar are perfect, it can still be difficult for people to understand them because of your pronunciation. Furthermore, it is advised that when learning a language, there are many things to study including vocabulary, grammar, reading, writing and speaking. A key to good speaking is good pronunciation (Sahatsathatsana, 2017). Ultimately, the components of speaking that might be considered in the assessment scale are grammar, pronunciation, fluency, content, organization and vocabulary (Mazdayasna, 2012).

However, several factors such as anxiety, fear of being despised, teacher strategy, and culture were found to influence the reluctance problem among speakers (Sava_ç1, 2014). Oral presentation is an effective communicative activity that has been widely adopted by EFL conversation teachers to promote oral proficiency. However, when oral presentations are assigned in class, the teacher will get either complete silence or grumbles from students who find the idea of oral presentations frustrating and intimidating. Students are overwhelmed with the research and communication skills that are necessary for a successful presentation. Some serious students who invest time and effort into an oral presentation do not always get the intended outcomes. Other students try to get through the ordeal as quickly as possible, but do not improve their speaking skills under such stressful situations. Thus, oral presentations can be a time-consuming project with no guarantee of a satisfactory performance (King, 2002).

\section{Solution}

Speaking of solutions or the effective ways of solving the problem in English oral presentation of the target students; it is essential to cope with anxiety and shyness. Anxiety and shyness are associated with many possible elements such as the abilities related to pronunciations, vocabularies, grammar, listening skill, speaking skill and so on. Dr. William Yaryan has shared that his students have difficulty speaking because they are shy and because they are afraid of making mistakes. Then, they think they have nothing to say. It is implied by this that it puts them under pressure in a way. He was trying to reassure them that practice will make shyness go away. And they do not have to speak perfectly. Then, the students have something to say if they have the vocabulary for it. Unquestionably, this is considered as an effective way to trigger right at anxiety and shyness and turn out to get students motivated to speak things out. It is an essential element contributing to improving speaking skill for the students. To clarify, the factors affected the issue of oral presentation of the target students 'pronunciation, vocabularies, grammar, fluency, thought organized, body language, visual aids, 
preparation, rehearsal, time management, and so on; will be disclosed. Once they are disclosed, it is an opportunity for teachers to be "top form" as being teachers to tackle in those details so as to improve the students' oral presentation performance.

Once the students are encouraged, they tend to enjoy oral presentations from the preparation phase till the show time or even after the Q\&A secession. Dr. Wisuttichai reveals that when the students share ideas the oral presentation as an effective method of and knowledge in group, the atmosphere in class will be filled with fun because they are learning the new things together. They will feel like they have a freedom to study, that's so called "unlimited learning”. English class as an interesting tool for either students and teachers are undeniable (Tsou, 2005).

In order to have the method of improving English presentation, it is inevitable to consider it as process as system. In other words, improving English oral presentation needs to be considered as a learning process systematically as shown below.

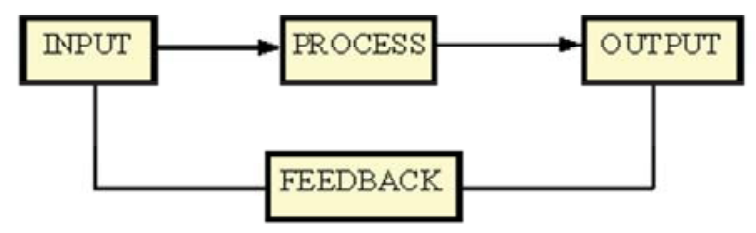

Figure 1 Feedback control system

(http://www.technologystudent.com/elec1/control1.htm) (V.Ryan, 2002 )

To apply the system, it will be mapping as in Figure 2.

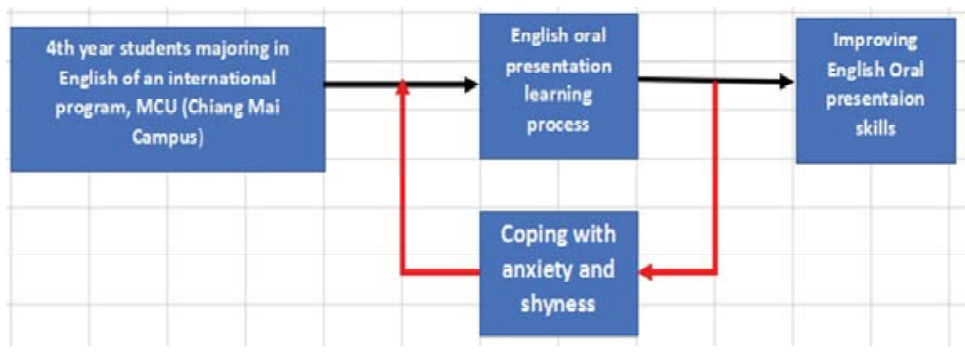

Figure 2 Feedback control system applied to the target students.

As a system, when we are talking about the feedback, it is something we have gained from the current situation; and going to be put back into the system in order to leverage or mechanize the current situation to turn out and meet what an objective is.

To put it differently, what is going on in the current situation as described in the conclusion mentioned earlier is that; the result is considered as output; which needs to be improved in order to come up with better skills in English oral presentation of the target students. As per the result of the study, alleviating anxiety and shyness could unlock the potential of those students and turn out to be improving their oral presentation as well as speaking skill. 
EnJourMe (English Journal of Merdeka): Culture, Language, and Teaching of English

Vol. 6, No. 1, Juli 2021, pp. 18-35

To simplify, anxiety and shyness is taken into consideration of key factors to unlock any blockages of oral presentation skill. Once the door is opened, the performance is going to be shown as it is in front of the teachers and audiences. In terms of "as it is", the ability related to pronunciation, vocabularies, grammar, confidence, strategies used, and so on will be portrayed so that the teachers can find more feedback to be given to the students in order to level up their oral presentation. For example, if the student has a problem with pronunciation, the teacher can come up with the strategy of "practicing makes perfect" to deal with that case. Further example, in case the student comes up with an issue of vocabulary, Penny Ur suggested that another useful strategy to increase impact is to use mnemonic devices, in particular the technique called 'keywords': students link the target word with an image involving a similar word in their own language (Ur, 2012). In addition, the two-time USA Memory Champion Ron White added that the problem is NOT with your memory. The problem is with the "Filing System" your brain currently uses to store and retrieve memory items. Change the filing system and you'll double and even triple your memory comprehension (White, 2013).

Dr. Sasinun has shared an interesting example that a Burmese student has a problem with speaking, she called his Burmese friend who is keen on English helps as a translator, three of them worked together. The teacher herself speaks English to communicate, the translator speaks Burmese for his friend. Then, the student who faces speaking problems gets improved step by step. Dr. Samran added a further example that he sometimes calls low level speaking skill students in individual to talk. He advised the techniques to fix their weak points. He assumed that encouragement is important to arouse the students to practice as he believes that everyone has great potential, they can be improved as much as possible.

Speaking about crucial feedback provided, it really helps if the student presentation is a VDO recorded for the teacher and the student to sit together providing feedback individually. The feedback can error correction in terms of pronunciation, vocabularies, grammar, body languages, eye contact, confidence, and so on; of which an optimum effectiveness and efficiency can be achieved to improve the English oral presentation.

It's easier to be said than done but both teachers and students need to mind and care time management wisely. The proper feedback provided in the right time counts. Ultimately, it's the most significant to deal with anxiety and shyness. In order to do so, the ability of teachers really depends upon experiences. Nonetheless, mindfulness meditation has been shown to be an effective stress management technique (Shearer et al., 2016). Mindfulness enhances emotion regulation and cognitive performance (Bellinger et al., 2015). In addition, it is revealed that mindfulness-based therapy is a promising intervention for treating anxiety and mood problems in clinical populations (Hofmann et al., 2010). Moreover, mindfulness has the potential to help individuals achieve more balance in their lives, especially during stressful times or when dealing with overwhelming emotional states (McCloskey, 2015).

\section{Conclusion and Suggestions}

This study investigates the ability and development in using English oral presentation of the fourth-year students, majoring in English (English Program) Mahachulalongkornrajavidyalaya Uni- 
English oral presentation for Bachelor of Arts of the four year international student at MCU Chiang Mai campus Thailand

Phra Natthakit Kittiyano (Thaipattana), Winai Siabthaisong

versity (Chiang Mai Campus). The conclusion relates directly to the research objectives (1) to study English presentation of Bachelor of Arts of the fourth-year international students in English at Mahachulalongkornrajavidyalaya University, Chiang Mai Campus; (2) to study the factors contributing to problems of oral presentation among students in English speaking classes; (3) to study the method in improving English presentation of Bachelor Arts of the fourth-year students in English at Mahachulalongkornrajavidyalaya University, Chiang Mai Campus. They have represented the contribution to knowledge, significance of the study in some other ways, to improve human condition. In this regard, the answer to the problems revealed in chapter 1 and 2. For the discussion, it refers to the objectives, and research questions. The meaning of results was evaluated and interpreted with mean, standard deviation and statistical significance carefully. And the suggestion was conducted with some limitations in the scope and procedure of the research.

The first suggestion addressed for students. As the teachers are promptly and help cope with anxiety and shyness, the opportunity to improve speaking skill and fluency by the process of learning English Oral Presentation classes is provided. Students need to pay attention, put effort, and spend time sufficiently since the preparation until the day you give the presentation. In addition, students need to focus on the feedback and see if practicing needed and is assigned, and need to take actions accordingly. Further, students need to learn to allocate time wisely from the very beginning. Once you are assigned for the oral presentation, they need to pay full attention to the preparation, study and do research on the subject, practice; so that they can be top form when it comes to your show time.

Next, suggestions for the teachers: (a) time should be allocated sufficiently, (b) promptly available to be consulted or asked for advice by the students, (c) proper feedback provided in the right time, (d) despite the fact that Lecturers (as per the depth interview) shows that they have provided technique, comments, feedback, assignment, attention, and so on; the teachers are inevitable to improve themself in terms of updating new knowledge. This is simply because the term "proper feedback" is associated with the experiences and knowledge of the teachers too, (e) explain the Purpose of Visual Aids, (f) help students to conquer the fear of making grammatical or pronunciation errors, (g) develop Students' Summarizing and Outlying Skills, and (h) emphasize the difference between Spoken English and Written English.

\section{References}

Akindele, D., \& Trennepohl, B. (2008). Breaking the culture of silence: Teaching writing and oral presentation skills to Botswana University students. Language, Culture and Curriculum, 21(2), 154-166.

Akkakoson, S. (2016). Speaking anxiety in english conversation classrooms among Thai students. Malaysian Journal of Learning and Instruction, 13(1), 63-82.

Al-Nouh, N. A., Taqi, H. A., \& Abdul-Kareem, M. M. (2014). EFL Primary School Teachers' Attitudes, Knowledge and Skills in Alternative Assessment. International Education Studies, 7(5), 68-84.

Alwi, N. F. B., \& Sidhu, G. K. (2013). Oral presentation: Self-perceived competence and actual performance among UiTM business faculty students. Procedia-Social and Behavioral Sciences, 90, 98-106. 
EnJourMe (English Journal of Merdeka): Culture, Language, and Teaching of English

Vol. 6, No. 1, Juli 2021, pp. 18-35

Bellinger, D. B., DeCaro, M. S., \& Ralston, P. A. S. (2015). Mindfulness, anxiety, and high-stakes mathematics performance in the laboratory and classroom. Consciousness and Cognition, 37, 123132.

Chamnan, V. T. (2017). AN ANALYTICAL STUDY OF ENGLISH SPEAKING SKILLS OF CAMBODIAN STUDENTS OF PREAH SIHANOUK RAJA BUDDHIST UNIVERSITY BATTAMBANG BRANCH.

Cheng, X. (2000). Asian students' reticence revisited. System, 28(3), 435-446.

Chuang, Y.-Y. (2009). A study of college EFL students' affective reactions and attitudes toward two types of performance-based oral tests. J. Educ. Res, 43, 55-80.

El Enein, A. H. A. A. (2011). Difficulties encountering English majors in giving academic oral presentations during class at Al-Aqsa University.

Elliot, J., \& Chong, J. L. Y. (2005). Presentation anxiety: A challenge for some students and a pit of despair for others. Available on: Http:/Mww. Isana. Org. Au/Files/20051017165939_PresentationAnxiety. Pdf.

Gao, H. (2013). On the Cultivation of Cross-culture Communication Competence of Second Language Learners. Theory \& Practice in Language Studies, 3(8).

Hofmann, S. G., Sawyer, A. T., Witt, A. A., \& Oh, D. (2010). The effect of mindfulness-based therapy on anxiety and depression: A meta-analytic review. Journal of Consulting and Clinical Psychology, 78(2), 169.

Hyland, K. (1991). Developing oral presentation skills. English Teaching Forum, 29(2), 35-37.

Kalra, R., \& Siribud, S. (2020). Public speaking anxiety in the Thai EFL context. LEARN Journal: Language Education and Acquisition Research Network, 13(1), 195-209.

Kholisoh, A., \& Farida, A. N. (2018). The Influences of Tongue Twister in Teaching Pronunciation of Aspirated Sound [Ph]. ELT Forum: Journal of English Language Teaching, 7(2), 63-72.

King, J. (2002). Preparing EFL learners for oral presentations. The internet TESL journal, 8 (3).

Leong, L. M., \& Ahmadi, S. M. (2017). AN ANALYSIS OF FACTORS INFLUENCING LEARNERS'ENGLISH SPEAKING SKILL.

Likitrattanaporn, W. (2014). Teaching Phonological Accuracy and Communicative Fluency at Thai Secondary Schools. English Language Teaching, 7(2), 1-10.

Lintunen, P., \& Skaffari, J. (2014). L2 English learners as public speakers: generic and language-specific features in learner narratives. AFinLA-e: Soveltavan Kielitieteen Tutkimuksia, 6, 45-63.

Liow, J.-L. (2008). Peer assessment in thesis oral presentation. European Journal of Engineering Education, 33(5-6), 525-537.

Mazdayasna, G. (2012). Objective assessment of oral presentations and EFL learners' speaking development. Journal of Foreign Language Teaching and Translation Studies, 1(1), 23-38.

McCloskey, L. E. (2015). Mindfulness as an intervention for improving academic success among students with executive functioning disorders. Procedia-Social and Behavioral Sciences, 174, 221226.

Munby, I. (2011). The oral presentation: an EFL teacher's toolkit.

Richards, J. C. (2015). Key issues in language teaching. Cambridge University Press. 
English oral presentation for Bachelor of Arts of the four year international student at MCU Chiang Mai campus Thailand Phra Natthakit Kittiyano (Thaipattana), Winai Siabthaisong

Sahatsathatsana, S. (2017). Pronunciation problems of Thai students learning English phonetics: a case study at Kalasin University. Journal of Education, Mahasarakham University, 11(4).

Savage, K. L., Bitterlin, G., \& Price, D. (2010). Grammar matters. New York: Cambridge UniversityPress.

Sava_ç1, M. (2014). Why are some students reluctant to use L2 in EFL speaking classes? An action research at tertiary level. Procedia-Social and Behavioral Sciences, 116, 2682-2686.

Shearer, A., Hunt, M., Chowdhury, M., \& Nicol, L. (2016). Effects of a brief mindfulness meditation intervention on student stress and heart rate variability. International Journal of Stress Management, 23(2), 232.

Suba_1, G. (2010). What are the Main Sources of Turkish EFL Students' Anxiety in Oral Practice? Turkish Online Journal of Qualitative Inquiry, 1(2).

Tran, N. N. (2011). Syllabus negotiation: a case study in a teriary EFL context in Vietnam. Language Education in Asia, 2(1), 71-91.

Tsou, W. (2005). Improving speaking skills through instruction in oral classroom participation. Foreign Language Annals, 38(1), 46-55.

Turner, K., Roberts, L., Heal, C., \& Wright, L. (2013). Oral presentation as a form of summative assessment in a master's level PGCE module: the student perspective. Assessment \& Evaluation in Higher Education, 38(6), 662-673.

Ur, P. (2012). A course in English language teaching. Cambridge University Press.

White, R. (2013). Memory improvement: How to improve your memory in just 30 days. Gildan Audio.

Wolfe, A. (2008). Oral presentations in marketing courses: Students' attitudes and self-assessment. Presentation \& Paper Published in the Proceeding in the Marketing Management Association (MMA) 13th Annual Fall Educators Conference, Louisville, Kentucky.

Wulandari, Z. N. (2019). THE INFLUENCE OF TONGUE TWISTER IN INDONESIAN STUDENTS'ABILITY IN PRONOUNCING/,/AND/ð/(An Experimental Study at the Tenth Grade Students of SMA Teuku Umar Semarang). UNNES.

Yazdanpanah, Z. (2012). The effect of explicit teaching of story structure on EFL learners' use of communication strategy. Procedia-Social and Behavioral Sciences, 32, 391-398.

Zappa-Hollman, S. (2007). Academic presentations across post-secondary contexts: The discourse socialization of non-native English speakers. Canadian Modern Language Review, 63(4), 455485. 